\section{A adaptação do pensamento evolutivo em sua circulação pública: o caso da revista "Evolution: a Journal of Nature", 1927-1938}

\author{
The adaptation of \\ evolutionary thinking in its \\ public circulation: the case \\ of "Evolution: a Journal of \\ Nature," 1927-1938
}

\section{Henrique Rodrigues Caldeira ${ }^{i}$}

' Doutorando, Departamento de História/Faculdade de Filosofia e Ciências Humanas/Universidade Federal de Minas Gerais. Belo Horizonte - MG - Brasil

orcid.org/0000-0001-8489-9313

henriquercaldeira@gmail.com

\footnotetext{
Ana Carolina Vimieiro Gomesii

ii Professora, Departamento de História/Faculdade de Filosofia e Ciências Humanas/Universidade Federal de Minas Gerais. Belo Horizonte - MG - Brasil

orcid.org/0000-0003-2527-6970

carolvimieiro@ufmg.br
}

Recebido em 25 jan. 2020

Aprovado em 9 jul. 2020.
CALDEIRA, Henrique Rodrigues; GOMES, Ana Carolina Vimieiro. A adaptação do pensamento evolutivo em sua circulação pública: o caso da revista "Evolution: a Journal of Nature", 1927-1938. História, Ciências, SaúdeManguinhos, Rio de Janeiro, v.28, n.4, out.-dez. 2021, p.961-981.

Resumo

O ensino de evolução foi objeto de intensa controvérsia nos EUA nas primeiras décadas do século XX. Em disputa, estava não apenas a validade da teoria, mas também a consideração de suas implicações éticas, políticas e religiosas. Este artigo analisa uma revista de popularização científica inserida nesse contexto, a Evolution: a Journal of Nature (1927-1938). O objetivo é demonstrar que a dinâmica de circulação pública do conhecimento representada pela revista não se resumiu a um processo de simplificação, eliminando detalhes e ressalvas pouco úteis ao público não especializado, mas antes consistiu em uma completa adaptação, confrontando criativamente o conhecimento científico com questões de grande importância na arena pública.

Palavras-chave: divulgação científica; conhecimento em trânsito; antievolucionismo; história do darwinismo; ciência e religião.

\section{Abstract}

The teaching of evolution was the subject of intense controversy in the United States in the first decades of the twentieth century. Both the validity of the theory and its ethical, political and religious implications were in dispute. This article analyzes a magazine intended to popularize science in this context, Evolution: a Journal of Nature (1927-1938). The objective is to demonstrate that the dynamics of the public circulation of knowledge represented by the magazine cannot be reduced to a process of simplification, eliminating details and exceptions of little use to the general public, but rather consisted of a complete adaptation, creatively connecting scientific knowledge to questions of great importance in the public arena.

Keywords: science communication; knowledge in transit; anti-evolutionism; history of Darwinism; science and religion. 
$\mathrm{E}^{\mathrm{s}}$ m 28 de fevereiro de 1922, o jornal The New York Times publicava o artigo "God and Jevolution", um dos principais marcos da campanha contra o ensino de evolução nas escolas norte-americanas. O texto era assinado pelo autor convidado Williams Jennings Bryan (1860-1925), político democrata três vezes candidato à presidência do país e exsecretário de Estado de Woodrow Wilson (Kazin, 2007). O artigo tocava em assuntos que iam do método científico à vida pessoal de Charles Darwin, mas a crítica de Bryan (28 feb. 1922, p.242) possuía um único foco, bastante preciso, em torno do qual tudo mais orbitava:

A única parte da evolução em que se sente um interesse considerável é a evolução aplicada ao homem. A hipótese no que diz respeito às rochas e à vida vegetal não afeta a filosofia sobre a qual a vida é construída. ... A evolução que é prejudicial - nitidamente - é a evolução que destrói a árvore genealógica do homem, conforme ensinada pela Bíblia, e faz dele um descendente de formas de vida inferiores. ${ }^{1}$

A preocupação quanto às implicações filosóficas da origem e do desenvolvimento humano parece ter sido realmente um elemento central na controvérsia pública acerca da teoria da evolução nos EUA no início do século XX. Ainda que o fato biológico da descendência com modificação já fosse ponto pacífico entre os naturalistas do período sendo objeto de discussão apenas os mecanismos explicativos do processo evolutivo (Bowler, 1992; Largent, 2009) -, lideranças religiosas conservadoras e setores do público leigo ainda resistiam militantemente a sua aceitação (Lienesch, 2007). Bryan não falava apenas por si, mas por um crescente movimento antievolucionista.

Durante o século XIX, a resistência ao evolucionismo nos EUA, sobretudo em suas expressões subsequentes às publicações de Darwin, havia permanecido razoavelmente contida entre os muros que circundavam a intelectualidade do país (Moore, 1979). Os discursos de antidarwinistas importantes, como o zoólogo de Harvard, Louis Agassiz (18071873), e o diretor do seminário presbiteriano de Princeton, Charles Hodge (1797-1878), apesar de influentes, tiveram um alcance bastante limitado, considerando a população total norte-americana (cf. Livingstone, 2001).

A questão ganhou contornos realmente amplos e populares apenas nas primeiras décadas do século XX, em decorrência da reformulação do ensino público nacional. Em um processo catalisado pela Primeira Guerra Mundial (1914-1918), as escolas secundárias (high schools), até então esvaziadas e dedicadas à preparação dos poucos alunos que visavam ingressar em uma universidade, transformaram-se em uma "educação para a vida", isto é, para melhor compreensão e interação com a realidade cotidiana, oferecendo também a capacitação profissional exigida pela nova realidade econômica norte-americana (Goldin, Katz, 1999). ${ }^{2}$

Nesse contexto, o número de estudantes frequentando essas escolas secundárias cresceu vertiginosamente. Em 1890, cerca de 360 mil alunos entre 14 e 17 anos haviam ingressado em uma delas, isto é, 6,7\% da população nesse grupo etário. Em 1920, o número já chegava a 2.500.000 alunos em todo o país, representando 32,3\% do mesmo grupo (DeBoer, 1991, p.39). Além disso, o currículo, antes restrito à leitura, escrita e aritmética, foi amplamente reformulado, constando uma recomendação nacional de que ao menos $25 \%$ de seu espaço fosse dedicado às ciências (DeBoer, 1991, p.41). 
Nesse cenário, a ideia de evolução foi apresentada pela primeira vez a inúmeros jovens e, colateralmente, a pais e lideranças comunitárias, produzindo assim as condições para um amplo debate sobre o tema. Como observou Andrew Jewett, falar em "ciência" nesse contexto era falar de muito mais do que um conjunto de conhecimentos, métodos ou instituições. No vocabulário dos reformadores progressistas da educação, "ser científico ... significava comportar-se de acordo com princípios éticos específicos ou exibir determinadas virtudes éticas. Significava um modo de falar, uma forma de relacionar-se, até mesmo uma maneira completa de viver" (Jewett, 2012, p.10). A esperança de tais reformadores era a de que, no contexto de turbulência e fragmentação social, a ciência servisse, de fato, como a "base para uma plena e coesa cultura moderna" (p.9).

Nesse projeto de modernização, a biologia ocupava um lugar central, promovendo comportamentos e valores associados ao reformismo progressista do período (Pauly, 2000). Um exemplo dessa imbricação entre biologia e reforma social é o livro didático amplamente adotado no período, Civic biology (1914), de George W. Hunter. Nele, os conteúdos da "ciência da vida" articulavam-se, a todo momento, com propostas políticas e sociais. A explicação da teoria celular conduzia à afirmação da necessidade e urgência de políticas públicas de saneamento, quarentenas e higiene pessoal. A seção sobre metabolismo refletia sobre os efeitos do álcool no organismo e sobre a importância de uma alimentação bem calculada. A exposição sobre reprodução e hereditariedade sugeria cuidados para uma vida sexual regrada, e assim por diante (cf. Shapiro, 24 set. 2008).

Como argumentou Adam R. Shapiro (2013, p.77), essa proposta de "cultura moderna" afirmava valores claramente situados no tempo e no espaço; tinha "origens nortistas, origens industriais, origens sindicalistas e origens progressistas". A partir da década de 1910, com a substituição do modelo de educação organizada municipalmente pela organização estadual (state level education), os novos currículos alinhados com essa reforma educacional passaram a alcançar não só as grandes metrópoles, mas também pequenas localidades rurais. Consequentemente, comunidades bastante tradicionais se viram obrigadas a adotar livros e currículos que lhes pareciam "uma tentativa de mudar sua cultura e incutir valores estrangeiros" (p.83).

Nesse contexto, lideranças locais começaram a se levantar contra o que consideravam uma intromissão das elites urbanas sobre a educação em sua região. A teoria da evolução, considerada a expressão máxima da "cultura moderna" (por razões que veremos adiante), iria se transformar no principal alvo desse protesto. Em contrapartida, cientistas, teólogos liberais e divulgadores da ciência também se lançariam com grande engajamento na polêmica criada em torno do assunto (Clark, 2008).

Um desses esforços pró-evolução que gostaríamos de destacar foi a publicação de popularização ${ }^{3}$ científica Evolution: a Journal of Nature (EJN). Lançada em dezembro de 1927 pelo ex-membro do Partido Socialista dos Estados Unidos (SPA) L.E. Katterfeld, ${ }^{4}$ a revista foi distribuída nacionalmente com o objetivo de "combater o fanatismo e a superstição e desenvolver a mente aberta pela popularização da ciência natural" (Katterfeld, Dec. 1927, p.8). Nesse esforço, seu conteúdo combinou reproduções de artigos científicos, contribuições originais de popularizadores, textos filosóficos de inspiração evolutiva, notícias e posicionamentos concernentes à situação do ensino e pesquisa no país e no mundo; além 
de piadas, versos e charges com representações do tema da evolução. Entre os autores da revista figuraram principalmente cientistas, professores, escritores e jornalistas. Seu preço, alinhado com seu objetivo de ampla circulação, era de apenas 10 cents por 16 páginas de conteúdo em preto e branco, com muitas imagens e pouca publicidade (Caldeira, 2018).

Esse rico mosaico, composto de conteúdos científicos, artísticos, éticos e políticos, expressa eloquentemente a diversidade de sentidos e interesses investidos na controvérsia acerca da evolução no país. Antes interpretada sob a chave "ciência versus religião", a controvérsia em questão tem sido abordada atualmente na historiografia como um fenômeno de maior complexidade, compreendendo perspectivas religiosas e pretensões científicas de ambos os lados, envolvendo projetos de reforma política, social e educacional antagônicos, e expressando formas de vida e orientações morais conflitantes (Larson, 2006; Lienesch, 2007; Moran, 2012; Numbers, 1993; Shapiro, 2013).

Alinhado a essa perspectiva, este artigo pretende demonstrar a multidimensionalidade do pensamento evolutivo conforme apresentado pela Evolution no curso de seu embate com o movimento antievolucionista nos EUA nas décadas iniciais do século XX. Mais especificamente, buscaremos demonstrar que a afirmação pública da teoria da evolução pela revista se valeu substancialmente, para além de exposições teórico-empíricas, de argumentos acerca de seu valor moral. Em outras palavras, discutiremos como "a evolução aplicada ao homem", ecoando os termos de Bryan, poderia "afetar a filosofia sobre a qual a vida é construída".

Ao longo deste artigo, argumentaremos que a circulação do pensamento evolutivo para um público mais amplo ao longo da controvérsia resultou em uma completa adaptação a tal situação histórica, com suas questões, valores e interesses característicos. Contra a "narrativa canônica" (Shapin, 1990) da popularização da ciência, isto é, o entendimento de que a comunicação da ciência para um público mais amplo consiste apenas em simplificação ou diluição do conteúdo produzido pelos especialistas, sustentaremos que, ainda que certos aspectos do conhecimento comunicado sejam realmente suprimidos em sua expressão pública, outros elementos são sempre adicionados, desenvolvidos e ressignificados.

No caso específico da revista Evolution, buscaremos demonstrar que, enquanto certos pormenores e nuanças do conhecimento relativo ao tema da evolução tenham sido frequentemente "simplificados" - como a distinção entre as teorias de Darwin e de outros autores, a especificidade dos processos biológicos em relação a outras dinâmicas naturais, e a pluralidade de interpretações coexistentes para as mesmas evidências -, outros elementos, desde considerações teológicas até prescrições políticas, foram nele investidos.

Esse fenômeno, naturalmente, não é algo exclusivo da documentação aqui analisada. A produção recente em história e filosofia da comunicação da ciência tem chamado atenção para essa dimensão criativa envolvida na circulação do conhecimento. Desde meados da década de 1990, pesquisadores têm questionado sistematicamente a suposição de uma divisão entre produção, comunicação e recepção da ciência. ${ }^{5}$ Como sintetizou Ralph O'Connor (2009, p.336), “o mosaico de estudos de caso na produção acadêmica atual confirma que a ciência popular funcionou não como um processo unidirecional de transferência de conhecimento, mas como uma rede heterogênea de trocas culturais e feedback entre diferentes grupos sociais". 
O médico e filósofo polonês Ludwik Fleck, no início do século XX, já havia proposto ideia semelhante. Segundo o autor, "a simples comunicação de um saber não é, de maneira alguma, comparável ao deslocamento de um corpo rígido no espaço euclidiano: nunca acontece sem transformação" (Fleck, 2010, p.163). Partindo das reflexões de Fleck, Bernardo Jefferson de Oliveira (2012, p.136) destaca que as ideias e técnicas são sempre "rearticuladas, ajustadas, aclimatizadas e adaptadas" ao "serem introduzidas num contexto social diferente do qual foram gestadas". Esse movimento, ainda segundo o autor, não resulta apenas em simplificação, mas também em "complexificação, pois são levados em conta vários outros fatores que a ciência artificialmente abstrai quando isola as variáveis, descontextualiza os fenômenos e os transpõe para uma arbitrária 'Condição Normal de Temperatura e Pressão'” (Oliveira, 2012, p.130, nota 7).

Ainda assim, a referida "narrativa canônica" permanece reinante fora do pequeno círculo de acadêmicos que se dedicam ao assunto. Este artigo pretende contribuir para esse esforço de demonstração do "outro lado da moeda" da circulação do conhecimento - a "complexificação". Além disso, ao analisarmos tal dinâmica por meio da revista Evolution, pretendemos contribuir também para a inclusão desse periódico - ainda tão pouco explorado - nos debates historiográficos acerca da controvérsia evolutiva norte-americana. ${ }^{6}$

Para isso, na primeira seção deste artigo, examinaremos a inserção da Evolution no contexto da disputa pelo ensino de evolução nos EUA. Destacaremos sua oposição ao principal grupo antievolucionista do período - os fundamentalistas - e analisaremos a autocompreensão da revista como parte desse embate. Na segunda seção, apontaremos algumas acusações de teor moral à teoria da evolução por parte dos fundamentalistas no contexto em análise e examinaremos como, em alguns momentos, autores de artigos da revista tentaram evitá-las recorrendo a uma delimitação da ideia de evolução, restringindo-a à explicação causal de fatos biológicos. Finalmente, na terceira seção, evidenciaremos como, em outros momentos, colaboradores da Evolution argumentaram a favor do valor mais que biológico do pensamento evolutivo, chegando a propô-lo como alternativa à cosmovisão tradicional religiosa.

\section{Guerra: a tese do conflito e a evolução como arma secularista na revista Evolution}

"Fundamentalistas anunciam nova campanha" (Katterfeld, Dec. 1927, p.8). Sob esse título, o primeiro editorial da revista Evolution: a Journal of Nature, de dezembro de 1927, informava seus leitores a respeito de um referendo que seria convocado no Arkansas. A população deveria votar, no ano seguinte, contra ou a favor da legalidade de escolas públicas do estado ensinarem que "o homem ascendeu ou descendeu de uma ordem inferior de animais". Essa "nova campanha" de fato representava uma novidade nos embates políticoeducacionais do período - não por investir legislativamente contra o ensino de evolução, mas por envolver diretamente a população em tal controvérsia.

Como já dito, opositores da teoria da evolução haviam se lançado publicamente em uma cruzada para banir tal conteúdo do currículo escolar desde, pelo menos, 1922. Recorrendo à dinâmica legislativa ordinária, isto é, obtendo a representação de um membro do Legislativo que pudesse propor um projeto de lei para votação no Congresso, o movimento 
tinha aprovado, até 1927, três leis contra o ensino de evolução no país (Oklahoma, 1923; Flórida, 1923; Tennessee, 1925). O resultado, contudo, parecia ainda insatisfatório para os antievolucionistas, que já haviam proposto mais de cinquenta resoluções em 21 estados do país. O movimento decidiu, então, aplicar uma nova tática: submeter a questão diretamente ao voto popular (Gray, 1970; Laats, 2010; Larson, 2003).

Os principais atores à frente desse projeto - e de todo o antievolucionismo norteamericano desde o início do século XX - foram os chamados "fundamentalistas". Apesar de o termo "fundamentalismo" ser comumente utilizado hoje, de modo genérico, para rotular expressões religiosas intransigentes ou violentas, sobretudo de matriz islâmica, sua origem remonta a um contexto bastante diferente: uma controvérsia teológica iniciada nos EUA na segunda metade do século XIX. Naquela época, dois grupos principais, os teólogos conservadores (autodesignados "fundamentalistas") e os teólogos liberais (também chamados de "modernistas"), engajaram-se em uma acirrada disputa pelo controle institucional das grandes igrejas protestantes do país (Longfield, 2000; Marsden, 1998).

Até os anos 1910, envolvido em tais disputas, o fundamentalismo preservaria um caráter marcadamente intelectual, circunscrito às polêmicas teológicas do período, tal como se expressa na publicação dos 12 volumes da obra antimodernista The fundamentals (1910-1915), para a qual teólogos de importantes igrejas e universidades norte-americanas e europeias contribuíram com artigos acerca de diversos temas cruciais da discussão teológica do período. Na década seguinte, porém, o movimento fundamentalista se tornaria crescentemente popular - tanto no sentido de alcançar e mobilizar maior público, quanto no de se desprender de sua origem acadêmica, assumindo um discurso cada vez mais inflamado no tom e menos sofisticado nos argumentos (Moore Jr., 1968; Sandeen, 1967).

O grande apelo do discurso fundamentalista se explica, em parte, pelo fato de que sua "religião", assim como a "ciência" dos reformadores progressistas da educação, desenvolveuse no cenário público norte-americano como algo muito maior do que asserções e práticas pontuais. Tratava-se, antes, de uma cultura completa, um alicerce suficiente para a edificação da nação. Se, inicialmente, ser fundamentalista significava aderir a um determinado modo de interpretar a Bíblia e a história e defendê-lo contra as "relativizações" propostas pelos teólogos liberais, nos anos 1920 ser fundamentalista tornara-se uma missão urgente para uma parte significativa da população, especialmente do Sul, que se via sob a ameaça da crescente irreligiosidade no país e de seus supostos efeitos nocivos nas mais diversas esferas da vida (Lienesch, 2007).

É importante lembrar que tal população mantinha suas raízes em uma realidade social, na qual "os jurados tinham de crer em Deus; os professores, de ler a Bíblia e, em alguns estados, uma observância religiosa do 'Dia do Senhor' era uma obrigação legal" (Commager, 1969, p.174). Resistia, ainda, uma realidade provinciana na qual a comunidade local e a congregação religiosa se confundiam; isto é, uma realidade radicalmente contrastante com a das metrópoles então florescentes no Norte: culturalmente diversas, demograficamente amontoadas e anônimas, e - no fraseado de Weber (2004, p.48) - "indiferentes a Deus e aos profetas".

Assim, agregando-se por meio de uma identidade religiosa comum, servindo-se de uma rede de mobilização já bem estabelecida (igrejas, institutos bíblicos e outros órgãos 
paraeclesiásticos) e empregando variados meios e estratégias de ação (promoção de debates públicos, lobby na esfera legislativa e uso acentuado da mídia), os fundamentalistas expandiram sua influência por todo o território norte-americano, tornando-se um poderoso grupo de pressão. E o principal alvo de seus ataques na década de 1920 seria, sem dúvida, a teoria da evolução (Lienesch, 2007).

A ideia de evolução era considerada por muitos fundamentalistas a epítome da depravação da civilização cristã, e tornara-se especialmente ameaçadora após sua penetração no sistema público de educação. A fixação pelo tema explicava-se por vários motivos. Além da já mencionada associação entre evolução e "cultura moderna", destacavam-se outras críticas mais pontuais. Segundo o principal porta-voz da campanha antievolucionista no período, William Jennings Bryan (1921, p.43), "a doutrina darwinista leva as pessoas ao agnosticismo e ao panteísmo, ... ela mergulhou o mundo na pior das guerras, e está dividindo a sociedade em classes que lutam entre si de modo animalesco". Se para Bryan, como para tantos outros fundamentalistas, a evolução estava na raiz do ateísmo, do militarismo alemão e da luta de classes, opor-se a ela se tratava de não menos do que defender, em uma só frente, a tradição cristã, a paz mundial e a coesão social no país (Laats, 2015, p.25-72).

$\mathrm{Na}$ visão dos defensores do ensino de evolução, no entanto, os fundamentalistas estavam fazendo uma só coisa: "Minando nosso sistema educacional". Segundo um editorial da Evolution escrito precisamente sob esse título, "crianças aos milhões esta[riam] sendo 'legalmente retardadas em seu desenvolvimento mental e moral' - e pela instigação de líderes religiosos!" (Whitenack, Sept. 1928, p.9; destaque nosso). A grande ameaça representada por esses, ainda segundo o editorial, não se resumiria a sua oposição pontual ao ensino de evolução, mas, de maneira mais geral, estaria em sua postura de detentores do "monopólio da verdade". "Não foi exatamente essa presunção a causa da execução de Sócrates, da crucificação de Jesus, da queima de Bruno, e da condenável humilhação de Galileu?", perguntava o editor. "E não irá ela destroçar nosso sistema educacional onde quer que seja posta em prática?" (p.9).

Compreender a imagem que a revista Evolution tinha de si mesma é de fundamental importância para compreender sua apresentação do pensamento evolutivo. Em suma, a revista considerou-se participante de um "conflito entre aqueles que veem a vida pelos olhos da ciência e aqueles que a veem sobretudo pelas superstições nebulosas do passado" (Katterfeld, Dec. 1927, p.8). Tal conflito, longe de ser tomado como algo específico de sua própria época, aparece na revista como uma dinâmica necessária e eterna, uma "guerra de extermínio" entre ciência e religião - ou liberdade e tradição -, a mesma em que lutaram Bruno, Galileu e Darwin, de um lado, e a Inquisição e os caçadores de bruxas, de outro.

Essa compreensão da relação histórica entre ciência e religião não é, como se sabe, um produto original da revista. Conhecida na historiografia como "tese do conflito", tal narrativa se desenvolveu na segunda metade do século XIX, num contexto de profissionalização da ciência e de secularização do ensino superior nos EUA e no Reino Unido. ${ }^{7}$ Nas páginas da Evolution, a "tese do conflito" integrou igualmente uma linguagem política secularista, marcada pela oposição à influência da religião sobre a atividade científica. Para os colaboradores da revista, promover a teoria da evolução e enfraquecer a autoridade eclesiástica parecia ser uma só missão. Como dito num editorial da revista, "O mais importante para a humanidade ... 
é a extensão e a democratização do conceito de evolução. Foi ele que derrubou a teologia medieval e completou a ampliação do horizonte mental da humanidade" (Crew, Mar. 1929, p.8). Nesse mesmo espírito, uma das capas da Evolution traz Charles Darwin como "o grande emancipador do intelecto humano" (ver Figura 1).

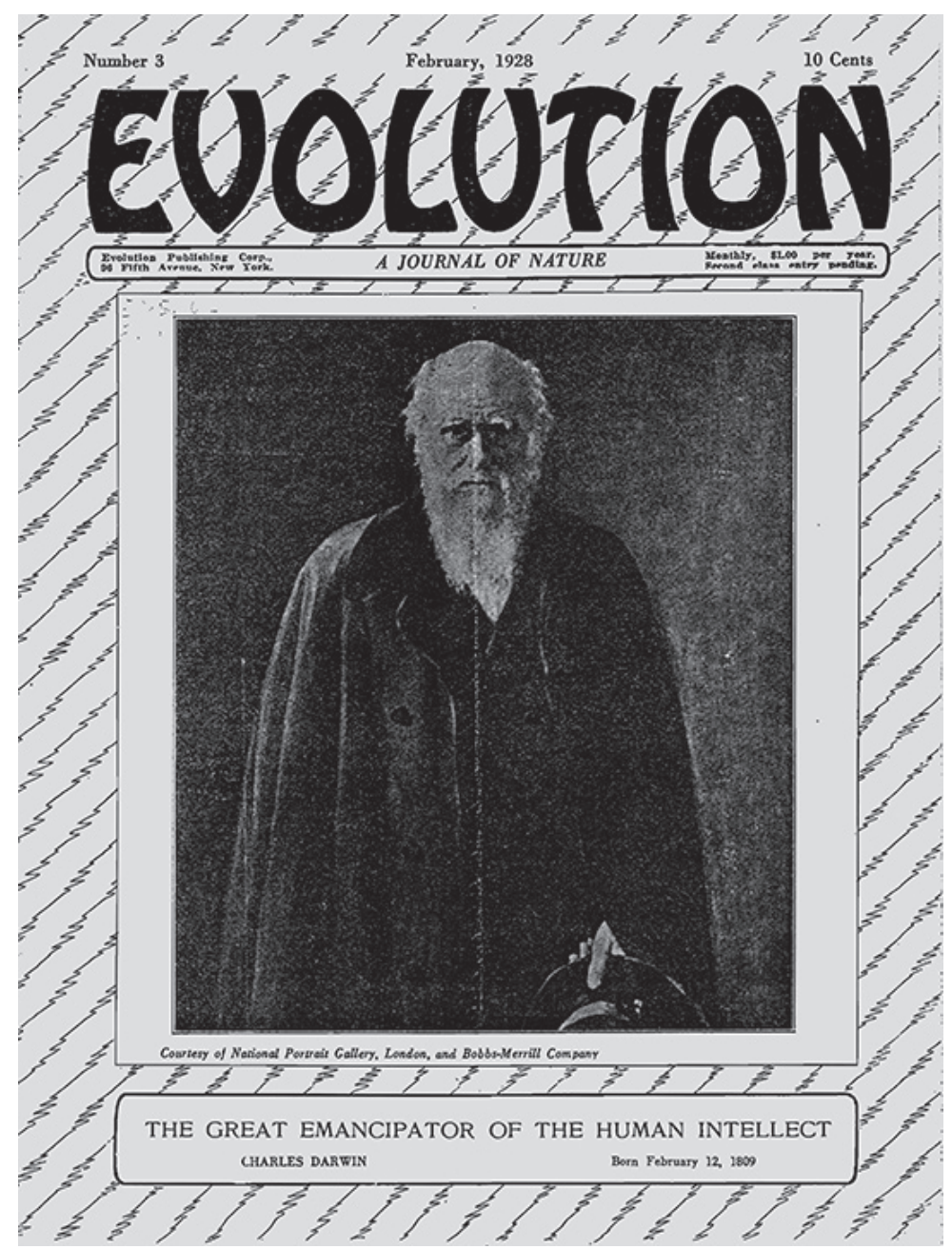

Figura 1: Fotogravura de Leopold Flameng, a partir de pintura a óleo de John Collier, genro de T.H. Huxley, 1881. A obra foi financiada pela Linnean Society of London para adornar a parede de um de seus saguões. Para um estudo dessa obra e outras representações pictóricas de Darwin, ver Browne (2009) (Evolution, v.2, n.2, capa)

A consciência de ser parte de um processo histórico de longuíssima duração, com inimigos claramente identificados e uma brilhante esperança à frente - a "emancipação do intelecto humano" - orientou de forma crucial não apenas a editoria e os colaboradores da revista, mas também o próprio público leitor em seu engajamento para com a publicação. Das 142 opiniões de leitores publicadas na sessão "From Our Readers", 48 se referem referem explicitamente à "guerra" travada entre a ciência e o pensamento religioso. Numa delas pode-se ler: "Sempre me emociono ao ouvir algo sobre a evolução e as ciências naturais; 
não porque isso seja meu hobby atual, mas porque sua missão [da evolução e das ciências naturais] é libertar o mundo da superstição e da escravidão" (Katterfeld, July 1928, p.14). "Sua revista é como um machado afiado cortando a árvore da teologia" (Katterfeld, Aug. 1928, p.14), escreve outro leitor. "Eu acho que ela [a revista Evolution] é um dos maiores passos já dados para derrotar a superstição e tirar o povo de suas escravidões mentais" (Katterfeld, Apr. 1928, p.14), elogia ainda outro.

Pode-se dizer que a complexa rede de sociabilidade costurada em torno da Evolution sustentou-se e manteve-se coesa, em grande medida, graças à cosmovisão e à compreensão histórica de seus agentes, unidos para combater o velho "fanatismo e a superstição" e inaugurar uma nova era da "mente aberta" pela popularização da ciência. Mas, afinal, que ciência seria essa? Como exatamente ela efetuaria essa emancipação intelectual da humanidade? Qual o papel do ensino de evolução nesse processo? E, mais ainda, o que seria exatamente a "teoria da evolução" promovida pelos autores da revista?

\section{Trincheira: a retração defensiva do conceito de evolução}

No primeiro artigo da primeira edição da revista, "Who believes in evolution?", David Starr Jordan (1851-1931), eminente zoólogo e cofundador da universidade de Stanford, define evolução nos seguintes termos: "a palavra evolução como comumente aceita compreende duas concepções distintas, a formação do universo material e o desenvolvimento da vida e da mente na Terra" (Jordan, Dec. 1927, p.2). Em outro artigo para a revista, "Meaning of evolution", Jordan (Jan. 1928, p.5) oferece uma definição ainda mais abrangente: "A teoria geral da evolução é bastante simples. Todos os objetos materiais mudam com o tempo e o espaço, e essas mudanças não são aleatórias, mas devidas a causas definidas; entretanto, como um todo e em particular, seguem um sistema ordenado".

Observa-se que as definições de Jordan aproximam fenômenos orgânicos e inorgânicos; vitais, mentais e materiais. Apresentam também o processo evolutivo como um fenômeno ordenado e que tende integralmente à ordem. Apesar de parecerem hoje deslocados, tais aspectos do entendimento do autor ressoavam com uma definição de evolução bastante comum na segunda metade do século XIX, influenciada, sobretudo, pelo pensamento de Herbert Spencer (1820-1903), autor de grande popularidade nos EUA em razão de sua perspectiva fortemente progressivista e de sua ética liberal (Moore, 1979, p.166-169).

O termo evolução, inicialmente associado ao desenvolvimento embriológico e à sucessão de formas verificadas no registro fóssil, receberia um novo sentido nos anos 1850, sobretudo nos países anglófonos, a partir da ampla circulação das obras de Spencer. O filósofo inglês, notadamente em sua obra em dez volumes A system of synthetic philosophy (1862-1897), propusera a unificação da filosofia universal sob a ideia de progresso, entendida como desenvolvimento gradual do mais simples para o mais complexo ou do homogêneo para o heterogêneo. Tal princípio deveria operar como chave interpretativa tanto para a história natural do cosmo, da vida e da mente quanto para a história social, cultural e política das tribos e civilizações humanas; afinal, todas essas variadas dimensões da realidade, para Spencer, estariam fundamentalmente integradas, formando um todo maior que a soma das partes, regido inteiro pela lei do progresso (Bowler, 1975). 
À luz desse histórico do conceito de evolução, podemos compreender melhor, entre outras coisas, a razoável frequência de artigos sobre astronomia e geologia na revista Evolution - 23 de 233, cerca de 10\% do total. Falar, por exemplo, da longuíssima história de formação do Grand Canyon ou da Via Láctea era também argumentar a favor da evolução em sentido mais geral, isto é, do desenvolvimento lento, gradual e progressivo verificável universalmente na natureza - em oposição radical, é claro, à concepção criacionista de um universo relativamente recente e em processo de decadência desde a Queda.

Contudo, a preponderância numérica dos artigos dedicados à evolução biológica, 152 (65\%), confirma sua situação de acentuado destaque em relação aos demais componentes do conceito mais amplo de "evolução". Isso se alinha tanto com os interesses da revista em seu confronto com os fundamentalistas, quanto com tônica do debate público e científico em geral. Na Evolution, a evolução biológica já se diferenciava em certa medida da evolução "cósmica", em sentido spenceriano - como sugere a própria bipartição do conceito de evolução proposto por Jordan ("duas concepções distintas", "material" de um lado e "vida e mente" de outro).

De fato, em um artigo na revista sobre a contribuição de Herbert Spencer para a teoria da evolução, o antropólogo da Universidade de Wisconsin, Alexander Goldenweiser, argumentou pela necessidade de restrição do conceito de evolução. Segundo ele, os três aspectos apontados por Spencer como característicos do fenômeno universal da evolução, a saber, uniformidade, gradualidade e progressividade, deveriam ser considerados "obsoletos ou, na melhor das hipóteses, imprecisos. Pois a evolução social ${ }^{8}$ não é uniforme nem sempre gradual, e não é necessariamente nem mesmo geralmente progressiva" (Goldenweiser, July 1928, p.2). No parecer de Goldenweiser, o esquema filosófico proposto por Spencer fora excessivamente ambicioso em sua pretensão sintética, comparando fenômenos incomparáveis, e, na opinião do autor, tal esquema já não resistiria à crítica e aos "fatos acumulados" pela antropologia moderna. ${ }^{9}$

Em seu artigo "What is evolution?", o autor de popularização científica Henshaw Ward (Dec. 1927) foi ainda mais assertivo quanto a uma restrição do conceito de evolução. "É espantoso ver como a 'evolução' é mal compreendida por pessoas educadas, às vezes até mesmo por cientistas" (p.5; destaque no original), lamenta o autor. Para esclarecimento, Ward apresenta uma história da ideia de evolução (sem o acréscimo "biológica" ou "orgânica"; simplesmente "evolução"), desde Aristóteles até Darwin, passando por Lucrécio, da Vinci e Lamarck, atentando-se exclusivamente à dimensão biológica do fenômeno. Além disso, Ward posiciona-se explicitamente contra a identificação do fenômeno da evolução orgânica com qualquer outro tipo de desenvolvimento inorgânico ou social, tal como fora comum nos anos anteriores. Segundo ele, "a evolução é uma teoria muito limitada. 'É puramente biológica'. Nenhum astrônomo pode partir dela para fazer uma história das nebulosas; nenhum sociólogo pode extrair dela qualquer lei de desenvolvimento social. Nenhum filósofo pode provar por ela alguma coisa sobre metafísica ou teologia" (Ward, Dec. 1927, p.6; destaque nosso).

Atentando-nos ao contexto de produção da revista, não é difícil compreender o empenho de autores como Ward e Goldenweiser no esforço de "isolar" a evolução biológica do conceito mais antigo e totalizante de evolução. Um argumento recorrente dos fundamentalistas 
contra o ensino de evolução no período fora o de que a implicação social da aceitação da teoria seria a desordem e a violência. Em 1921, como já dito, William Jennings Bryan (1921, p.43) havia afirmado "que a doutrina darwinista ... lançou o mundo na pior das guerras". A ideia de que a promoção da caótica "lei da selva" resultaria no abandono da "reta conduta cristã" era central em seu discurso. Nas suas palavras: "a fera presente no homem é trazida à superfície graças à teoria que faz o homem acreditar ser parente de sangue das feras" (p.43). Isto é, considerar-se um animal seria o primeiro passo para agir como um. E a maior prova disso, para Bryan e outros antievolucionistas, havia sido a Primeira Guerra Mundial.

Curiosamente, era à publicação de um cientista, e não à de uma liderança religiosa, que Bryan recorria para associar a evolução ao conflito global. Tratava-se do livro Headquarter nights (1917), escrito pelo zoólogo darwinista norte-americano Vernon Kellogg (1867-1937). Entre 1915 e 1916, Kellogg atuara como voluntário na Bélgica vestindo e alimentando civis afligidos pela guerra. Durante esse período, tivera oportunidade de participar de jantares da alta cúpula militar alemã, nos quais tomou conhecimento, segundo sua compreensão, da centralidade da teoria da evolução na ideologia militarista germânica. Nas palavras de Kellogg (1917, p.28), "o credo da Allmacht de uma seleção natural baseada em competição violenta e fatal é o evangelho dos intelectuais alemães; todo o resto é ilusão e anátema". A Allmacht [onipotência] da seleção natural era a afirmação principal do "neodarwinismo", posicionamento teórico encabeçado pelo zoólogo alemão August Weismann (1834-1914), que afirmava ser a seleção natural mecanismo explicativo suficiente para a evolução. Segundo Kellogg (1917, p.29), inspirados pela ênfase completa de Weismann na dimensão deletéria do fenômeno (eliminação do menos apto) como motor do progresso das espécies, os oficiais alemães acreditavam que a guerra "não apenas deve continuar, pois esta é a lei natural, mas precisa continuar, de modo que esta lei natural possa realizar de maneira cruel e inevitável a salvação da espécie humana".

Outra polêmica quanto à aplicação imediata das novas conclusões da biologia evolutiva a outros campos do saber - menos presente no discurso fundamentalista, mas frequente como crítica acadêmica, sobretudo entre antropólogos - teve como objeto a "teoria da recapitulação", sobretudo na vertente proposta por Ernst Haeckel (1834-1919)..$^{10}$ Segundo o naturalista alemão, o desenvolvimento dos indivíduos de espécies "superiores" passaria por uma série de etapas nas quais estaria representada a forma adulta de espécies ancestrais "inferiores" (Gould, 1991, p.111). Por exemplo, no desenvolvimento embrionário dos humanos, poderiam ser identificadas características da forma adulta de peixes (guelras) ou répteis (cauda). Essa interpretação filogenética das evidências embriológicas seria explorada por Haeckel como importante argumento a favor da ancestralidade comum das espécies e, mais especificamente, para fundamentar sua reconstrução de árvores evolutivas (Bouquet, 1996, p.55-59).

Evocando a ideia de recapitulação, diversos autores, sobretudo nacionalistas ingleses, franceses e alemães, afirmariam que sua própria raça - caucasianos ou arianos - representaria a fase adulta da humanidade, enquanto negroides e mongoloides (utilizando as categorias raciais de então) representariam a infância da espécie (Gould, 1991; Regal, 2004). Dentro de uma compreensão alargada de evolução, o mesmo tipo de hierarquização poderia se aplicar às respectivas culturas e organizações sociais dos diferentes povos. Como se sabe, 
tal raciocínio serviria como importante base científica para as justificativas racialistas das dominações imperialistas dos séculos XIX e XX (Bowler, 2003, p.297).

No contexto de publicação da revista Evolution, após a Primeira Guerra Mundial, essa pretensa identificação de princípios e conclusões biológicas com ações políticas e militares soava particularmente perigosa. Portanto, para defender a evolução biológica diante de um público ainda assombrado pelos horrores de tal evento, como o público norte-americano dos anos 1920, era necessário "salvá-la" da velha e maculada concepção totalizante da teoria, inclusive criticando-a, diferenciando-se de seus antigos defensores (Largent, 2009). Em outras palavras, o momento favorecia uma retração defensiva do conceito de evolução por meio da interdição de certas conexões entre as ciências naturais e outros campos do saber.

Dito isso, não estranha que, em um artigo a respeito de Haeckel na revista Evolution, Alexander Goldenweiser se refira à teoria da recapitulação - segundo Stephen J. Gould (1991, p.112), uma das "ideias mais influentes da ciência do final do século XIX" - como "uma noção muito tola" e lamente que as ciências sociais tenham caído "sob o encanto das ideias evolutivas", causando "muito obscurecimento e erro" (Goldenweiser, Apr. 1928, p.2). Segundo o autor, a distinção entre evolução na natureza e nas sociedades humanas era absolutamente clara: "Não se pode esperar que uma lei orgânica de crescimento se aplique a séries históricas baseadas na transferência e acumulação da tradição" (p.2). Estabelecida essa distinção, isto é, rejeitada a abordagem totalizante da evolução - parece-nos dizer o autor - não há por que temer a teoria.

Curiosamente, esse anseio por uma limitação do conceito de evolução, teoricamente restrito e exclusivamente biológico, tão importante para assegurar uma boa imagem pública para os evolucionistas do pós-guerra, convive, de forma ambivalente, na revista Evolution - bem como nos debates públicos e acadêmicos norte-americanos do período - com uma significativa adaptação do conceito em outras direções, aplicado e transformado no contato com as mais diversas discussões políticas, éticas e religiosas prementes no período.

O próprio Alexander Goldenweiser, que no artigo sobre Haeckel lamentara a aproximação das ciências sociais com as perspectivas e conclusões da evolução biológica, não rechaça, entretanto, essa mesma dinâmica - parece até mesmo aprová-la - em seu artigo sobre o naturalista, anarquista e ex-príncipe russo Peter Kropotkin (1842-1921). Em sua obra Mutualismo (1902), Kropotkin posicionara-se contra a ideia então em voga de que um comportamento egoísta e violento fosse o mais vantajoso para o sucesso biológico, propondo, em seu lugar, a primazia das relações de cooperação, ou mutualismo. A intenção principal do pensador anarquista, naturalmente, não era apenas atacar o mito da "lei do mais forte" na natureza, mas questioná-lo também em suas expressões sociais, políticas e econômicas (Ferretti, 2018).

Nos EUA, a relativização da moral a partir da crença de que o caminho para o progresso fosse o "vale-tudo" da competição biológica tornara-se bastante comum na expressão pública da teoria. ${ }^{11}$ Como admitia Goldenweiser (Mar. 1928, p.3), "a doutrina biologicamente inspirada da luta pela sobrevivência, na qual o fraco perece e o poderoso conquista, exerceu uma influência sinistra no pensamento sociológico e político". Contudo, segundo ele, "Darwin nunca pretendeu enfatizar" a interpretação individualista e belicista da evolução, foram "popularizadores menos escrupulosos" (p.3) que o fizeram. Contra tal ênfase, o 
autor destaca o trabalho de Kropotkin, o qual, a partir da história natural dos cavalos, dos burros e dos bodes, afirmara a importância da cooperação intra e interespecífica como fator de progresso:

Não satisfeito em ter demonstrado a importância do mutualismo no reino animal, Kropotkin levou suas pesquisas para o campo da sociedade primitiva e depois para as cidades da Europa medieval e as cooperativas de trabalhadores modernos. Kropotkin, bem documentado e brilhante, serve como contraponto necessário às distorções unilaterais da teoria darwiniana original (Goldenweiser, Mar. 1928, p.3).

Curiosamente, a sugestão de caráter não pouco totalizante de Kropotkin, a saber, que o mutualismo é a mais importante relação na dinâmica zoológica, antropológica e sociológica, parece passar sem críticas pelo crivo de Goldenweiser. De fato, essa articulação entre evolução e elementos da tradição socialista não era algo inédito no contexto de publicação da revista Evolution. Desde os tempos de Lamarck e de Darwin, intelectuais de esquerda buscaram, de diversos modos, articular o pensamento evolutivo com seus projetos revolucionários. A questão do materialismo e a ênfase na transformação e no progresso estiveram no centro dessas reflexões (Pittenger, 1987; Stack, 2000). O Partido Socialista dos Estados Unidos, do qual Goldenweiser fora membro entre 1915 e 1929 (McGee, Warms, 2013, p.349), havia sido formado no contexto da Segunda Internacional, alinhado com sua forte ênfase na ciência, em geral, e no pensamento evolutivo, em particular (Blackledge, Kirkpatrick, 2002). Em periódicos socialistas de então, lia-se, nesse espírito, que as "descobertas científicas são armas no arsenal da classe trabalhadora" e "não há trabalho que possa produzir tanta riqueza em informações valiosas para o trabalhador socialista quanto o estudo da ciência natural" (Cotkin, 1984, p.205).

Assim, se, por um lado, os autores da revista Evolution interditaram certas relações entre evolução e certos saberes e posicionamentos políticos e científicos; por outro lado, esses mesmos autores não se eximiram de adaptar o pensamento evolutivo a seus próprios valores, compreensões e expectativas sociais. É o que se verifica abundantemente nas páginas da publicação.

\section{Movimento: a expansão moral do pensamento evolutivo}

Um dos exemplos mais expressivos da expansão valorativa da teoria da evolução na revista é, certamente, o artigo "The ethics of evolution", de Maynard Shipley (June 1931, p.14), fundador da organização antifundamentalista Science League of America, que o inicia garantindo: "É impossível enfatizar demais o valor ético do conceito evolutivo". Para o autor, a acusação dos fundamentalistas de que "a filosofia evolucionista é brutalizante e essencialmente imoral" (p.14) é absolutamente infundada e resulta da ignorância a respeito do "princípio grandioso e enobrecedor de mutualismo, tal como ensinado por Darwin e fortemente enfatizado por Kropotkin". A história evolutiva, na interpretação de Shipley, mostra que "o homem, 'especialmente', não pode viver sozinho. Ele nunca poderia ter evoluído para o seu estado atual com base no egoísmo estrito ou no individualismo" (p.14; destaque no original). 
Além de defender o altruísmo e a vida comunitária a partir de uma leitura progressivista da história natural da espécie, Shipley condena, do mesmo modo, os vícios sociais humanos como características primitivas, "vestígios" do desenvolvimento evolutivo, comparáveis ao apêndice e aos terceiros molares - ideia que também é defendida em "Mind and morals", de Hugh F. Munro (Oct. 1928, p.3). A citação é longa, mas importante:

Apesar dos altos e baixos da história humana, no geral, a raça humana tem se tornado cada vez melhor. Quando os meninos e meninas aprendem que são ... os sobreviventes de uma raça muito antiga que tem, no geral, avançado para frente e para o alto na proporção em que seus membros aprendem que a virtude é ela mesma a recompensa, que a gentileza, a decência e o fair play sozinhos podem conquistar para eles um lugar alto e seguro na sociedade - quando eles aprenderem 'que mesquinhez, egoísmo e brutalidade são evidências de reversão para um estágio bruto mais primitivo na evolução do homem', eles irão valorizar a beleza de uma conduta ideal e fazer o melhor possível para tornar nosso mundo um lugar mais satisfatório e agradável para se viver (Shipley, June 1931, p.14).

Ao tirar lições éticas da história evolutiva, Maynard Shipley não agia, por assim dizer, como um profeta solitário, mas como sacerdote de uma religião já bem estabelecida. Desde meados do século XIX, cientistas norte-americanos, empenhados no processo de sua profissionalização, haviam buscado legitimar seu ofício junto ao público apresentando a ciência como instrumento moralizante. ${ }^{12}$ Como já dito, a organização da biologia como disciplina nos EUA esteve explicitamente ligada a um projeto de reforma social. Tratavase de um conhecimento, nas palavras de Philip Pauly (1991, p.171), "ao mesmo tempo ostentosamente objetivo e carregado de valores"; isto é, ao mesmo tempo em que postulava a realidade positiva do mundo natural, a biologia expressava uma série de valores, legitimados na qualidade de "dados da natureza", que se relacionavam, por sua vez, a um determinado ideal de sociedade - moderna, industrial, cosmopolita e secular.

É nesse contexto que se situam afirmações como as de Shipley (June 1931, p.14) de que "aprender as leis do universo é aprender também que devemos obedecer a essas leis ou então perecer. Moralidade consiste, em última análise, em obediência às leis da natureza"; ou que "evolução não apenas dá unidade e direção ao estudo da cultura humana como um todo, e que a ciência moderna é ininteligível sem ela, mas também que essa disciplina tem grande valor como uma agência educacional" (p.14).

Claramente, Maynard Shipley não segue seu colega já mencionado Henshaw Ward na perspectiva conceitual restritiva de que a evolução é "puramente biológica". No artigo "What evolution means to you", o autor chega a dizer claramente que "não apenas o conceito de evolução é necessário para uma compreensão real das ciências naturais, como ele é essencial em 'todos os campos do bem-estar humano'", como na "indústria de plantas e de animais, em medicina, cirurgia, geologia, zoologia, psicologia, origem humana, estudo da criança, criminologia e penologia - em suma, em todos os departamentos do conhecimento humano" (Shipley, Mar. 1928, p.9; destaque nosso).

Como já dissemos, Maynard Shipley não é o único autor na revista Evolution a atribuir um sentido - explicativo e orientador - tão abrangente à evolução. Ao contrário, esse deslocamento da ciência evolutiva na direção dos mais diversos debates predomina no curso 
de toda a publicação. Outro exemplo é o texto "Evolution and the new perspectives of life purposes", de Harry Elmer Barnes (mar. 1928, p.7), professor de história da Universidade de Columbia. O artigo começava com a asserção de que "concepção evolucionista e a nova cosmologia são tão perturbadoras para as visões aceitas acerca do homem como o são para a antiga atitude teológica para com Deus" (p.7). Na opinião do autor, não se pode mais sustentar a "teoria bíblica", segundo a qual o ser humano é uma "entidade teológica", ora exaltado como "pouco inferior aos anjos", ora rebaixado como "um verme sobre a terra". "Os fatos científicos", diz Barnes, "revelam que o homem não é nem um verme nem um anjo de asas cortadas. Ele é o principal membro do grupo dos símios e, portanto, o elemento dominante até então no reino animal" (p.7).

A oposição estabelecida pelo autor é curiosa. Ao comparar as duas abordagens - bíblica e evolutiva -, Barnes parece conferir a elas certa equivalência de natureza e função gnosiológica, isto é, parece confrontá-las como resultados distintos de dinâmicas de conhecimento idênticas, ou respostas distintas relativas a perguntas idênticas, ou, ainda, como lances feitos em um mesmo "jogo de linguagem". ${ }^{13}$ Quando se atenta para o fato de que a comparação bíblica do homem com anjos (Salmos 8:4) ou com vermes (Salmos 22:6) surge como expressão eminentemente poética no contexto da composição de salmos, isto é, de louvores musicais judaicos, parece pouco preciso classificá-la como uma "teoria bíblica" e colocá-la em oposição direta com observações e teorizações circunscritas à descrição do mundo em sua apresentação material. Do mesmo modo, parece pouco relevante à validade de tais expressões o que os "fatos científicos revelam". Contudo, ao estabelecer essa comparação frontal entre Bíblia e biologia, Barnes parece apresentá-las como ocupantes de um mesmo espaço do saber, de modo que seja forçada uma escolha por uma ou outra. Nesse movimento, é como se a religião fosse arrastada até o território da ciência para aí perecer sob seus critérios.

Como argumenta Harry Elmer Barnes (Mar. 1928, p.7):

Se fosse verdade que somos anjos ligeiramente mitigados, isso não daria nenhuma pista para o estudo da humanidade, porque ninguém viu um anjo e não possuímos conhecimento dos 'traços pessoais e padrões de comportamento' da hoste angélica. Por outro lado, uma vez que reconhecemos o fato de o homem ser um animal, temos imediatamente os ricos campos da anatomia comparativa, fisiologia e psicologia, baseado nas quais podemos construir uma abordagem sólida para o estudo da natureza e do comportamento humanos (destaque nosso).

Aqui, a ideia da substituição da visão bíblica pela biológica soa realmente como uma verdadeira mudança de paradigma científico, abrindo novas possibilidades de investigação, trazendo à tona novos dados e prometendo conclusões superiores acerca do mesmo objeto de estudo. Nesse mesmo espírito, Barnes (Mar. 1928, p.7) chega a posicionar folclore, teologia e psicologia primatológica ao longo de uma mesma linha de desenvolvimento científico para concluir que "o estudo da psicologia dos símios ... oferece mais na busca de uma chave para a compreensão do comportamento humano do que todos os livros de teologia já compilados desde os dias do folclore primitivo até o mais abstruso manual apologético de um professor contemporâneo de teologia sistemática". E continua: 
Mesmo um livrinho bem-humorado e assumidamente trivial como This simian world de Clarence Day [escritor novaiorquino] ensinará mais coisas relevantes e convincentes sobre a natureza humana do que os tomos pesados de um [Tomás de] Aquino ou os sermões coletados de uma dúzia de [Dwight L.] Moodys ou [Charles H.] Spurgeons [evangelistas norte-americano e britânico, respectivamente] (Barnes, Mar. 1928, p.7).

De modo interessante, esse movimento de aproximação com fins de comparação entre ciência e religião acaba levando também a ciência a significativas transformações. Se a compreensão do ser humano como quase anjo ou quase verme resultava de e em considerações existenciais acerca de seu lugar no mundo, a compreensão do ser humano como "o principal membro do grupo dos símios" (Barnes, Mar. 1928, p.7), proposta em substituição a ela, deveria suprir também as mesmas demandas por sentido às quais a primeira "definição" atendia. No movimento de substituir uma compreensão religiosa da humanidade por uma científica, esta última acaba tendo que assumir os papéis tradicionalmente assumidos pela religião, como, por exemplo, o de educação moral, orientação e coesão social e até mesmo de esclarecimento quanto ao sentido da vida.

Nesse sentido, dirá Barnes (Mar. 1928, p.7), as "implicações da [definição] acima para a sociologia e a ética são muito grandes e realmente abrangentes". Segundo o autor, o "tipo de comportamento e as instituições que melhor se adéquam ao avanço da felicidade e da eficiência humana devem ser procurados e construídos em conformidade com a necessidade de uma espécie de supersímios que habitam diversos tipos de ambiente geográfico" (p.7). Isto significaria que a orientação política e social moderna deveria ter como base o estudo científico da espécie humana, o qual, por sua vez, deveria se basear fundamentalmente na primatologia, abordada de modo comparativo. Mas não só. Segundo Barnes (Mar. 1928, p.7), as atuais contribuições da ciência como um todo, desde as descobertas astrofísicas até as antropológicas, "tornaram necessária uma revolução completa nas visões aceitas sobre o propósito da vida". Dessa forma, num movimento complementar ao analisado anteriormente, a ciência se desloca rumo a um território tradicionalmente ocupado pela religião - o do sentido da vida -, e, na opinião do autor, alcança aí nova vitória. Afinal, em face da ciência moderna,

Esta Terra não pode mais ser considerada um campo de treinamento temporário, preparatório para a vida na Nova Jerusalém. Em vez disso, ela pode ser racionalmente considerada no presente 'unicamente' lugar no qual o homem deve tornar-se o mais feliz possível durante sua existência temporária nesta Terra. Não só 'devem os objetivos da vida humana ser reduzidos a um plano secular', mas agora nós devemos definitivamente enunciar e defender 'o direito de ser feliz' (Barnes, Mar. 1928, p.7; destaques nossos).

Completa-se assim a defesa de Barnes da superioridade absoluta, em todos os aspectos descritivos e prescritivos; objetivos e valorativos; biológicos, sociológicos e metafísicos - da ciência (especialmente a biologia) sobre a religião (sobretudo o cristianismo fundamentalista). Desse modo, compreende-se por que a revista Evolution apostou na promoção da ciência, representada principalmente pelo conceito de evolução, contra os fundamentalistas e, mais amplamente, contra qualquer "força repressiva" vista sob a perspectiva da "tese do conflito". 
De acordo com a compreensão de diversos autores da revista, a evolução expressava um conjunto de valores para a ciência e para a sociedade, as quais deveriam ser amplamente secularizadas, retiradas do alicerce tradicional religioso e recolocadas sobre um alicerce "objetivo", no qual a própria natureza, incontaminada de erros humanos, expressaria os valores definitivos para o progresso social e o aperfeiçoamento humano.

\section{Considerações finais}

A revista Evolution: a Journal of Nature teve como objetivo promover o pensamento evolutivo em um contexto específico: a controvérsia norte-americana do início do século XX sobre o ensino de evolução nas escolas. Como qualquer ambiente - como um laboratório, um acampamento de pesquisa ou uma conferência acadêmica -, a arena pública ocupada com essa questão teve suas particularidades: suas próprias perguntas, preocupações, referências simbólicas e sensibilidades. Para sobreviver nesse ambiente, a teoria da evolução não poderia ser indiferente a tais pressões. Teria que se adaptar.

O que buscamos ilustrar ao longo deste artigo foi precisamente a mutabilidade do conceito de evolução, conforme este foi apresentado ao longo da publicação da Evolution. De artigo para artigo, de editorial para editorial, o conceito se transformou, adequando-se ao contexto específico no qual estava sendo evocado, respondendo às questões que eram então mais urgentes e ignorando elementos considerados pouco úteis ou desfavoráveis. Algumas vezes, entrincheirando-se contra associações e extrapolações perigosas, malditas no imaginário público, o conceito se retraiu, recuando para a segurança da objetividade e da neutralidade de valores. Outras vezes, oferecendo-se como guia para a solução de desafios éticos, políticos e sociais, o conceito se avolumou em alcance e sentido, movimentandose para espaços de debate totalmente diversos. Assim, mais do que apresentar rudimentos da teoria da evolução, omitindo detalhes e traduzindo jargões, a Evolution adaptou criativamente, com expressiva ambivalência, o conhecimento científico que se empenhou em popularizar.

Compreender essa dinâmica é fundamental para não perdermos de vista a interação viva e necessária entre ciência e sociedade, tanto no passado quanto no presente. Ainda hoje, o tema da evolução continua a incitar debates que vão muito além de discordâncias acerca de fatos ou métodos. ${ }^{14}$ Se quisermos favorecer discussões mais profícuas, não podemos ignorar o fato de que em todos os lados das polêmicas atuais, como nas do passado, estão vivamente presentes valores, ideais de sociedade e até mesmo concepções acerca do propósito de nossa existência na Terra, que não podem ser de modo algum desconsiderados.

\section{AGRADECIMENTOS}

Agradecemos à Coordenação de Aperfeiçoamento de Pessoal de Nível Superior (Capes) o financiamento da pesquisa que resultou neste artigo. Agradecemos também aos membros do grupo Scientia: Grupo de Teoria e História da Ciência, da Universidade Federal de Minas Gerais - suas valiosas contribuições. Finalmente, agradecemos aos pareceristas anônimos que contribuíram decisivamente para o aprimoramento deste artigo. 


\section{NOTAS}

${ }^{1}$ Nessa e nas demais traduções de textos em outros idiomas a tradução é livre.
${ }^{2}$ O período de reconstrução nacional após a Guerra Civil foi marcado por intenso desenvolvimento industrial
e expansão dos centros urbanos, resultando em novas demandas, relações e especializações profissionais. A
capacidade da sociedade de acompanhar o ritmo das mudanças estruturais do país foi uma questão premente
no período. A diversidade de propostas para ordenar o caos aparente deu o tom do que Hofstadter (1955)
chamou de a Era das Reformas (1890-1940), na qual se situa a referida reforma educacional.

${ }^{3}$ Apesar das discussões contemporâneas acerca da pertinência do termo "popularização", optamos por manter o rótulo que a revista aplicou sobre si mesma.

${ }^{4}$ Katterfeld emigrara do Império Alemão para os EUA ainda criança. No país, completou sua educação básica e ingressou no curso de sociologia em Topeka, no Kansas, onde se filiou ao partido socialista. Concorreu ao governo do estado de Washington e, mais tarde, foi secretário do partido em Moscou. De volta ao país, acabou preso e, aos poucos, afastou-se do partido para dedicar-se a outra frente: a divulgação científica. Para um estudo mais completo da trajetória do editor, ver Caldeira (2018).

${ }^{5}$ Ainda que trabalhos mais antigos como os de Ludwik Fleck (2010), originalmente publicado em 1935, já trouxessem elementos para tal discussão, foi o artigo de Cooter e Pumfrey (1994) que suscitou um prolífico debate entre especialistas da área, intensificado pelo artigo de Secord (2004) e destacado na seção "Focus" do v.100, n.2, da revista Isis (ver Bensaude-Vincent, 2009; Daum, 2009; O'Connor, 2009; Pandora, 2009; Topham, 2009). Uma ótima introdução a esse debate é o texto de Oliveira (2012).

${ }^{6}$ O historiador Joe Cain (2003), da University College London, tornou pública a série completa digitalizada da Evolution em 2003, acompanhada de uma nota geral de três páginas. Após isso, pouquíssimos trabalhos, entre os quais se destacam os de Constance A. Clark $(2008,2009)$, remeteram a essa documentação. Caldeira (2018) é, até então, o único trabalho de fôlego que utilizou a revista como objeto central. Evolution pode ser acessada livremente pelo site da Biodiversity Heritage Library (BHL): https://www.biodiversitylibrary. org/bibliography/7766. Acesso em: 10 jan. 2020.

${ }^{7}$ As obras seminais de tal tese são History of the conflict between religion and science (1874), de John William Draper, e A history of the warfare of science with theology in Christendom (1896), de Andrew Dixon White. Para um contraponto direto e atual a tal "tese", ver Harrison (2006). Para uma avaliação historiográfica do desenvolvimento e das apropriações da "tese do conflito", ver Hardin, Numbers e Binzley (2018).

${ }^{8}$ Destacamos que a expressão "evolução social", na frase de Goldenweiser, remete ao assunto discutido por ele no parágrafo anterior, a "teoria da evolução social conforme formulada por Herbert Spencer"; portanto, não deve ser entendida necessariamente como vocabulário próprio e aprovado pelo autor.

${ }^{9}$ Discípulo do relativista cultural Franz Boaz (1858-1942), Goldenweiser não poderia aceitar a teoria progressivista das "etapas" do desenvolvimento civilizacional, defendida por Auguste Comte e também sugerida por Spencer.

${ }^{10}$ Ainda que tal princípio tenha sido associado fortemente à figura de Haeckel, variantes dessa ideia foram propostas, antes e depois, por numerosos outros autores (Mayr, 1994). No Brasil, por exemplo, Fritz Müller, naturalista-viajante do Museu Nacional, do Rio de Janeiro, já havia enunciado em 1864, a partir da observação de um anelídeo tubícola, que o desenvolvimento embrionário manifestava fases morfológicas distintas, as quais remetiam gradualmente a estruturas de espécies "inferiores". Na interpretação de Müller, sugeria-se, assim, que "formas históricas primitivas" ficavam preservadas na embriogênese (Papavero, 2003).

${ }^{11}$ Defendendo o laissez-faire econômico e eximindo-se moralmente de sua prática monopolista, o empresário do ramo do petróleo John D. Rockefeller, por exemplo, afirmara que o "crescimento de um grande negócio é simplesmente a sobrevivência do mais apto [e] a operação de uma lei da natureza" (citado em Hofstadter, 1955, p.4).

${ }^{12}$ Francis Bowen (1811-1890), filósofo de Harvard, argumentava, por exemplo, em 1849, que o estudo objetivo da natureza revelaria um sistema de leis morais em radical contraste com a "mácula do egoísmo" verificada na sociedade industrial. Para ele, o estudo moderno da natureza deveria incluir a "ciência geral da natureza humana", composta pelas "ciências especiais da ética, psicologia, estética, política e economia política" (Jewett, 2012, p.37). A todo esse pacote, Bowen dava o nome de "ciência do dever" (science of duty). Da mesma forma que as leis da física e da química ordenavam o comportamento dos astros e dos elementos, as leis da "ciência do dever" deveriam servir para ordenar o comportamento humano. Descobri-las e difundi-las era a esperança e missão dos cientistas para restaurar a ordem "natural", desejável, da sociedade. 
${ }^{13}$ Em suas Investigações filosóficas, Ludwig Wittgenstein (2009) desenvolve o conceito de "jogos de linguagem" (Sprachspiels), que compara cada "linguagem e as atividades com ela entrelaçadas" (\$7) com jogos, isto é, com dinâmicas regidas por regras próprias, nas quais o sentido da comunicação não se dá pela fala em si mesma, mas pela relação da fala (ou "lance") com as demais peças, lances, limitações e possibilidades do "jogo". Isto é, um mesmo enunciado, quando deslocado de um jogo para outro, terá seu significado inevitavelmente alterado ou até mesmo anulado.

${ }^{14}$ Desde 2005, foram propostos pelos menos setenta projetos de lei antievolucionistas nos EUA (Matzke, 2016). No Brasil, circulam hoje dois projetos de lei demandando a inserção do criacionismo no ensino público e privado (PL 8090/2014, de autoria do pastor Marco Feliciano, e PL 5336/2016, de autoria de Jefferson Campos).

\section{REFERÊNCIAS}

BARNES, Harry Elmer. Evolution and the new perspective of life purposes. Evolution: A Journal of Nature, p.7, Mar. 1928.

BENSAUDE-VINCENT, Bernadette. A historical perspective on science and its 'others'. Isis, v.100, n.2, p.359-368, 2009.

BLACKLEDGE, Paul; KIRKPATRICK, Graeme. Historical materialism and social evolution. New York: Palgrave Macmillan, 2002.

BOUQUET, Mary. Family trees and their affinities: the visual imperative of the genealogical diagram. The Journal of the Royal Anthropological Institute, v.2, n.1, p.43-66, 1996.

BOWLER, Peter J. Evolution: the history of an idea. Berkeley: University of California Press, 2003.

BOWLER, Peter J. The eclipse of Darwinism: antiDarwinian evolution theories in the decades around 1900. Baltimore: Johns Hopkins University Press, 1992.

BOWLER, Peter J. The changing meaning of 'evolution'. Journal of the History of Ideas, v.36, n.1, p.95-114, 1975.

BROWNE, Janet. Looking at Darwin: portraits and the making of an icon. Isis, v.100, n.3, p.542-570, 2009.

BRYAN, William Jennings. God and evolution. The New York Times, Seção S, p.84, 28 Feb. 1922.

BRYAN, William Jennings. The Bible and its enemies. Chicago: The Bible Institute Colportage Association of Chicago, 1921.

CAIN, Joe. Publication history for 'Evolution: a Journal of Nature'. Archives of Natural History, v.30, n.1, p.168-171, 2003.

CALDEIRA, Henrique Rodrigues. 'Evolution: a Journal of Nature': ciência, evolução $e$ fundamentalismo nos Estados Unidos, 19271938. Dissertação (Mestrado em História)Universidade Federal de Minas Gerais, Belo Horizonte, 2018.
CLARK, Constance Areson. "You are here": missing links, chains of being, and the language of cartoons. Isis, v.100, n.3, p.571-589, 2009.

CLARK, Constance Areson. God - or Gorilla: images of evolution in the Jazz Age. Baltimore: Johns Hopkins University Press, 2008.

COMMAGER, Henry Steele. O espírito norteamericano: uma interpretação do pensamento e do caráter norte-americano desde a década de 1880. São Paulo: Cultrix, 1969.

COOTER, Roger; PUMFREY, Stephen. Separate spheres and public places: reflections on the history of science popularization and science in popular culture. History of Science, v.32, n.97, p.237-267, 1994.

COTKIN, George. The socialist popularization of science in America, 1901 to the First World War. History of Education Quarterly, v.24, n.2, p.201-214, 1984.

CREW, F.A.E. Important to humanity. Evolution: A Journal of Nature, p.8, Mar. 1929.

DAUM, Andreas W. Varieties of popular science and the transformations of public knowledge: some historical reflections. Isis, v.100, n.2, p.319-332, 2009.

DEBOER, George E. A history of ideas in science education: implications for practice. New York: Teachers College Press/Columbia University, 1991.

FERRETTI, Federico. Evolução e revolução: os geógrafos anarquistas Elisée Reclus e Pëtr Kropotkin e sua relação com a ciência moderna, séculos XIX e XX. História, Ciências, SaúdeManguinhos, v.25, n.2, p.553-568, 2018.

FLECK, Ludwik. Gênese e desenvolvimento de um fato científico. Belo Horizonte: Fabrefactum, 2010 .

GOLDENWEISER, Alexander. Spencer and the Synthetic Philosophy. Evolution: A Journal of Nature, p.2-3, July 1928. 
GOLDENWEISER, Alexander. Ernst Haeckel and the Ontogenetic Law. Evolution: A Journal of Nature, p.2-3, Apr. 1928.

GOLDENWEISER, Alexander. Thomas H. Huxley and Peter Kropotkin. Evolution: A Journal of Nature, p.3, Mar. 1928.

GOLDIN, Claudia; KATZ, Lawrence F. Human capital and social capital: the rise of secondary schooling in America, 1910-1940. Journal of Interdisciplinary History, v.29, n.4, p.683-723, 1999.

GOULD, Stephen Jay. A falsa medida do homem. São Paulo: Martins Fontes, 1991.

GRAY, Virginia. Anti-evolution sentiment and behavior: the case of Arkansas. The Journal of American History, v.57, n.2, p.352-366, 1970.

HARDIN, Jeff; NUMBERS, Ronald L.; BINZLEY, Ronald A. (org.). The warfare between science and religion: the idea that wouldn't die. Baltimore: Johns Hopkins University Press, 2018.

HARRISON, Peter. "Science" and "religion": constructing the boundaries. The Journal of Religion, v.86, n.1, p.81-106, 2006.

HOFSTADTER, Richard. The Age of Reform: from Bryan to F.D.R. New York: Vintage Books, 1955.

JEWETT, Andrew. Science, democracy, and the American university. New York: Cambridge University Press, 2012.

JORDAN, David Starr. Meaning of evolution. Evolution: A Journal of Nature, p.5-6, Jan. 1928.

JORDAN, David Starr. Who believes in evolution? Evolution: A Journal of Nature, p.2, Dec. 1927.

KATTERFELD, L.E. From our readers. Evolution: A Journal of Nature, p.14, Aug. 1928.

KATTERFELD, L. E. From our readers. Evolution: A Journal of Nature, p.14, July 1928.

KATTERFELD, L.E. From our readers. Evolution: A Journal of Nature, p.14, Apr. 1928.

KATTERFELD, L.E. Our name; our policy: fundamentalists announce new campaign. Evolution: A Journal of Nature, p.8, Dec. 1927.

KAZIN, Michael. A godly hero: the life of William Jennings Bryan. New York: Anchor, 2007.

KELLOGG, Vernon Lyman. Headquarters nights: a record of conversations and experiences at the headquarters of the German Army in France and Belgium. New York: Atlantic Monthly Press, 1917.

LAATS, Adam. The other school reformers: conservative in American education. Cambridge: Harvard University Press, 2015.
LAATS, Adam. Fundamentalism and education in the Scopes Era. New York: Palgrave Macmillan, 2010.

LARGENT, Mark A. The so-called eclipse of Darwinism. Transactions of the American Philosophical Society, v.99, n.1, p.3-21, 2009.

LARSON, Edward J. Summer for the gods: the scopes trial and America's continuing debate over science and religion. Cambridge: Basic Books, 2006.

LARSON, Edward J. Trial and error. New York: Oxford University Press, 2003.

LIENESCH, Michael. In the beginning: fundamentalism, the scopes trial, and the making of the antievolution movement. Chapel Hill: The University of North Carolina Press, 2007.

LIVINGSTONE, David N. Darwin's forgotten defenders. Vancouver: Regent College Publishing, 2001.

LONGFIELD, Bradley J. For church and country: the fundamentalist-modernist conflict in the Presbyterian Church. The Journal of Presbyterian History, v.78, n.1, p.35-50, 2000.

MARSDEN, George M. Understanding fundamentalism and evangelicalism. Grand Rapids, Michigan: W.B. Eerdmans, 1998.

MATZKE, Nicholas J. The evolution of antievolution policies after Kitzmiller v. Dover. Science, v.351, n.6268, p.28-30, 2016.

MAYR, Ernst. Recapitulation reinterpreted: the somatic program. The Quarterly Review of Biology, v.69, n.2, p.223-232, 1994.

MCGEE, R. Jon; WARMS, Richard L. (org.). Theory in social and cultural anthropology: an encyclopedia. Los Angeles: Sage, 2013.

MOORE, James. The post-Darwinian controversies. New York: Cambridge University Press, 1979.

MOORE JR., Leroy. Another look at fundamentalism: a response to Ernest R. Sandeen. Church History, v.37, p.195-202, 1968.

MORAN, Jeffrey P. America Genesis: the evolution controversies from scopes to creation science. New York: Oxford University Press, 2012.

MUNRO, Hugh F. Mind and morals. Evolution: A Journal of Nature, p.3, Oct. 1928.

NUMBERS, Ronald L. The creationists: the evolution of scientific creationism. Berkeley, California: University of California Press, 1993.

O'CONNOR, Ralph. Reflections on popular science in Britain: genres, categories, and historians. Isis, v.100, n.2, p.333-345, 2009. 
OLIVEIRA, Bernardo Jefferson de. Os circuitos de Fleck e a questão da popularização da ciência. In: Condé, Mauro Lúcio Leitão (org.). Ludwik Fleck: estilos de pensamento na ciência. Belo Horizonte: Fino Traço, 2012. p.121-144.

PANDORA, Katherine. Popular science in national and transnational perspective: suggestions from the American context. Isis, v.100, n.2, p.346-358, 2009.

PAPAVERO, Nelson. Fritz Müller e a comprovação da teoria de Darwin. In: Domingues, Heloisa Maria Bertol; Sá, Magali Romero; Glick, Thomas (org.). A recepção do darwinismo no Brasil. Rio de Janeiro: Editora Fiocruz, 2003. p.29-44.

PAULY, Philip J. Biologists and the promise of American life. Princeton: Princeton University Press, 2000.

PAULY, Philip J. The development of high school biology: New York City, 1900-1925. Isis, v.82, n.4, p.662-688, 1991.

PITTENGER, Mark. Science, culture and the new socialist intellectuals before World War I. American Studies, v.28, n.1, p.73-91, 1987.

REGAL, Brian. Human evolution: a guide to the debates. Santa Barbara: ABC-Clio, 2004.

SANDEEN, Ernest R. Toward a historical interpretation of the origins of fundamentalism. Church History, v.36, n.1, p.66-83, 1967.

SECORD, James A. Knowledge in transit. Isis, v.95, n.4, p.654-672, 2004.
SHAPIN, Steven. Science and the public. In: Olby, R.C. et al. (org.). Companion to the history of modern science. New York: Routledge, 1990. p.990-1007.

SHAPIRO, Adam R. Trying biology: the scopes trial, textbooks, and the antievolution movement in American schools. Chicago: The University of Chicago Press, 2013.

SHAPIRO, Adam R. Civic biology and the origin of the school antievolution movement. Journal of the History of Biology, v.41, n.3, p.409-433, 24 set. 2008.

SHIPLEY, Maynard. The ethics of evolution. Evolution: A Journal of Nature, p.14, June 1931.

SHIPLEY, Maynard. What evolution means to you? Evolution: A Journal of Nature, p.9, Mar. 1928.

STACK, David. The first Darwinian left: radical and socialist responses to Darwin, 1859-1914. History of Political Thought, v.30, n.4, p.682-710, 2000.

TOPHAM, Jonathan R. Introduction. Isis, v.100, n.2, p.310-318, 2009.

WARD, Henshaw. What is evolution? Evolution: A Journal of Nature, p.5-6, Dec. 1927.

WEBER, Max. Ciência e política: duas vocações. São Paulo: Cultrix, 2004.

WHITENACK, Oscar O. Undermining our educational system. Evolution: A Journal of Nature, p.8-9, Sept. 1928.

WITTGENSTEIN, Ludwig. Investigações filosóficas. Petrópolis: Vozes, 2009.

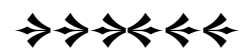

